\title{
Fabrication of ZnO Nanoparticles for Photocatalytic Reduction of $\mathrm{CO}_{2}$
}

\author{
Guang NI ${ }^{1, \mathrm{a}}$, Yinfei $\mathrm{CHEN}^{1, \mathrm{~b}}$, Yulan $\mathrm{LIU}^{1, \mathrm{c}}$, Huayan LIU ${ }^{1, \mathrm{~d},}$ and Zekai ZHANG ${ }^{1, \mathrm{e}^{*}}$ \\ ${ }^{1}$ College of Chemical Engineering, Zhejiang University of Technology, Chaowang road 18, 310014 \\ Hangzhou, China

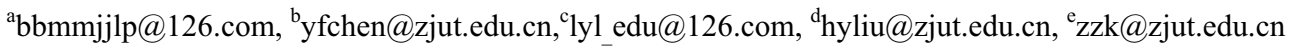

\begin{abstract}
ZnO}$ nanoparticles were fabricated by anodization method. Different fabrication conditions, including $\mathrm{pH}$ buffers (sodium hydroxide, citric acid, oxalic acid, hydrogen peroxide), electrolyte concentration, temperature and voltage were investigated. The field emission scanning electron microscopes (FESEMs) revealed that zinc oxide nanoparticles with discal morphology were formed. The optimum conditions for fabrication of nano $\mathrm{ZnO}$ material with discal shape nanoparticles are $1 \mathrm{wt} \%$ $\mathrm{NH}_{4} \mathrm{~F}$ electrolyte in water ethano $(1: 1)$ solution at $25^{\circ} \mathrm{C}$ and $40 \mathrm{v}$ with $0.2 \mathrm{M}$ citric acid as $\mathrm{pH}$ buffer. This $\mathrm{ZnO}$ material shows rather high photocatalytic reduction activity of $\mathrm{CO}_{2}$ and the yield of $\mathrm{CH}_{4}$ reaches 2.48 umol/g catalyst.
\end{abstract}

Keywords: Zinc oxide nanoparticles, discal morphology, preparation conditions, photocatalytic reduction

\section{Introduction}

Zinc oxide has drawn considerable attention because of its attractive optical-electrical characteristics[1,2] that make it potentially applicable in a lot of fields such as ultraviolet lasing[3], photocatalysts[4] and so on[5,6]. In addition, 1D nanoscale $\mathrm{ZnO}$ is preferred in photoanode applications due to its larger surface area[7].

Anodic oxidation has been employed in synthesis of many kinds of metal oxides with 1D nanostructure[8 10]. Research on anodization of various valve metals by P. Schmuki group[11 14] showed that anodizing can be applied to the preparation of nanostructures of other valve metals. Anodization of Znthat is one of the valve metals especially synthesis of $1 \mathrm{D}$ nanoscale of $\mathrm{ZnO}$ by anodizing has been widely investigated, since its gentle conditions and cheap equipment. S. Sreekantan et al.[7] have reported that nanoneedle, nanoflower and nanoflake of $\mathrm{ZnO}$ can be obtained by anodization in different concentration of sodium hydroxide. Apiked $\mathrm{ZnO}$ nanowire structures[15] are achieved by changing the $\mathrm{NH}_{4} \mathrm{~F}$ concentration. Studies on the preparation of $\mathrm{ZnO}$ strips have been conducted by Sung Joong Kim et al[16].

Although many researches have concentrated on $1 \mathrm{D}$ nanoscale $\mathrm{ZnO}$, research of various nanostructures in this field is still at primary stage. Hence, the new morphology and application of $\mathrm{ZnO}$ nanoparticle is yet to be further found. The key to nanostructure of $\mathrm{ZnO}$

*Corresponding author: zzk@zjut.edu.cn 
synthesized by anodizing is the balance of the formation and dissolution of $\mathrm{ZnO}$. It is known that anodic zinc oxide is very easily dissolved in strong acidic or basic conditions[17]. In this paper, we prepared $\mathrm{ZnO}$ nanoparticles with discal morphology by carefully adjustment of $\mathrm{pH}$ buffer and other conditions. This $\mathrm{ZnO}$ material is supposed to be good for application of photoelectricity due to its regular structures such as large absorption area and flat surface beneficial to electronic transmission. The influence of preparation conditions such as electrolyzer vemperature, voltage, etc are explored in detail. Furthermore, its photoncatalytic reduction activity of $\mathrm{CO}_{2}$ is conducted and its yield of $\mathrm{CH}_{4}$ is observed.

\section{Experimental}

Zinc foils (20-mm thickness) with a purity of $99.99 \%$ were purchased from Qingyuan company of metal materials. A zinc plate with size of $20 * 40 * 0.02 \mathrm{~mm}$ was cleaned with acetone and ethanol in an ultrasonic bath for $10 \mathrm{~min}$. Subsequently, to remove the oxide layer on the surface, it was polished by the $\mathrm{NaOH}$ solution of concentration $0.3 \mathrm{~mol} / \mathrm{l}$, washed with ethanol 3-5 times and dried with a stream of $\mathrm{N}_{2}$ gas. The anodization was carried out by using a two-electrode system consisting of the zinc foil and a platinum foil as anode and cathode, respectively. The distance between anode and cathode was $50 \mathrm{~mm}$. At the first stage, anodic etching was conducted in $1 \mathrm{wt} \% \mathrm{NH}_{4} \mathrm{~F}$ aqueous solution with different $\mathrm{pH}$ buffer (sodium hydroxide, citric acid, oxalic acid, hydrogen peroxide) at $25 \mathrm{oC}$ and $40 \mathrm{~V}$ for $10 \mathrm{~min}$. Next, different anodization conditions including electrolyte $\left(\mathrm{H}_{2} \mathrm{O}, \mathrm{H}_{2} \mathrm{O}: \mathrm{C}_{2} \mathrm{H}_{5} \mathrm{OH}\right.$ 1:1, $\mathrm{H}_{2} \mathrm{O}$ : glycol $\left.1: 1\right)$, temperature $\left(25,35,45^{\circ} \mathrm{C}\right)$, voltage $(40,50,60 \mathrm{v})$ and $\mathrm{NH}_{4} \mathrm{~F}$ quality score $(0.5 \%, 1 \%, 1.5 \%)$ are investigated. The stirring rate was kept constant during the anodization.

The morphology and composition of anodic zinc oxides were characterized by a field emission scanning electronmicroscope (FE-SEM, Hitachi S-4700, Japan), operated at an accelerating voltage of $15 \mathrm{kV}$.

Photocatalytic reduction of $\mathrm{CO}_{2}$ was conducted in a sealed stainless steel reactor having a quartz window through which the sample can be exposed to light. The reaction system contains $0.1 \mathrm{MPa} \mathrm{CO}_{2}$ and $2 \mathrm{ml} \mathrm{H}_{2} \mathrm{O}$. A $300-\mathrm{W}$ Xe lamp is light source. The weight of anodic zinc oxides is about $0.01 \mathrm{~g}$. Reaction products were analyzed by a Techcompa gas chromatograph (GC7900) equipped with thermal conductivity detector and a Shimadzu gas chromatograph (GC-2014) equipped with flame ionization detector.

\section{Results and Discussion}

\subsection{Feature of Anodic Zinc Oxide}

The morphologies of $\mathrm{ZnO}$ obtained by anodic dissolution with different $\mathrm{pH}$ buffer (sodium hydroxide, citric acid, oxalic acid, hydrogen peroxide ) for $1 \mathrm{~min}$ are shown in Fig. 1. It is nature to find that the shape of $\mathrm{ZnO}$ depends on the types of the $\mathrm{pH}$ buffer, as it has been reported that zinc oxide can exist neither in strong acidic nor basic conditions[17]. Layers of anodic zinc oxide come out with the addition of hydrogen peroxide (Fig. 1a). The layers of $\mathrm{ZnO}$ are finally formed by $\mathrm{ZnO}$ nanoparticles from the reaction of hydroxide ions and $\mathrm{Zn}^{2+}$ ions at the initial stage[18]. Fig. $1 \mathrm{~b}, 1 \mathrm{c}$ and $1 \mathrm{~d}$ show that the smaller concentration of hydrogen ion, the more regular $\mathrm{ZnO}$ nanoparticles. It can be explained by this reaction as follows $[16,19]$ : 


$$
\begin{aligned}
& \mathrm{ZnO}+2 \mathrm{H}^{+} \rightarrow \mathrm{Zn}^{2+}+\mathrm{H}_{2} \mathrm{O} \\
& \mathrm{ZnO}+2 \mathrm{~F}^{-} \rightarrow \mathrm{ZnF}_{2}+\mathrm{O}_{2}^{-} \\
& \mathrm{ZnO}+4 \mathrm{NH}_{4}^{+} \rightarrow \mathrm{Zn}\left(\mathrm{NH}_{3}\right)^{2+}+\mathrm{H}_{2} \mathrm{O}+2 \mathrm{H}^{+} . \text {(3) }
\end{aligned}
$$

Reaction (1) can aggravate the dissolution of $\mathrm{ZnO}$ nanoparticles, as disk-like nanoparticles presented in Fig. 1c and Fig. 1d. Appropriate concentration of hydrogen ion may be favorable for the balance between generation and dissolution. The amount and the uniformity of the $\mathrm{ZnO}$ nanoparticles prepared with $0.2 \mathrm{M}$ citric acid (Fig. 1d) is the optimum.
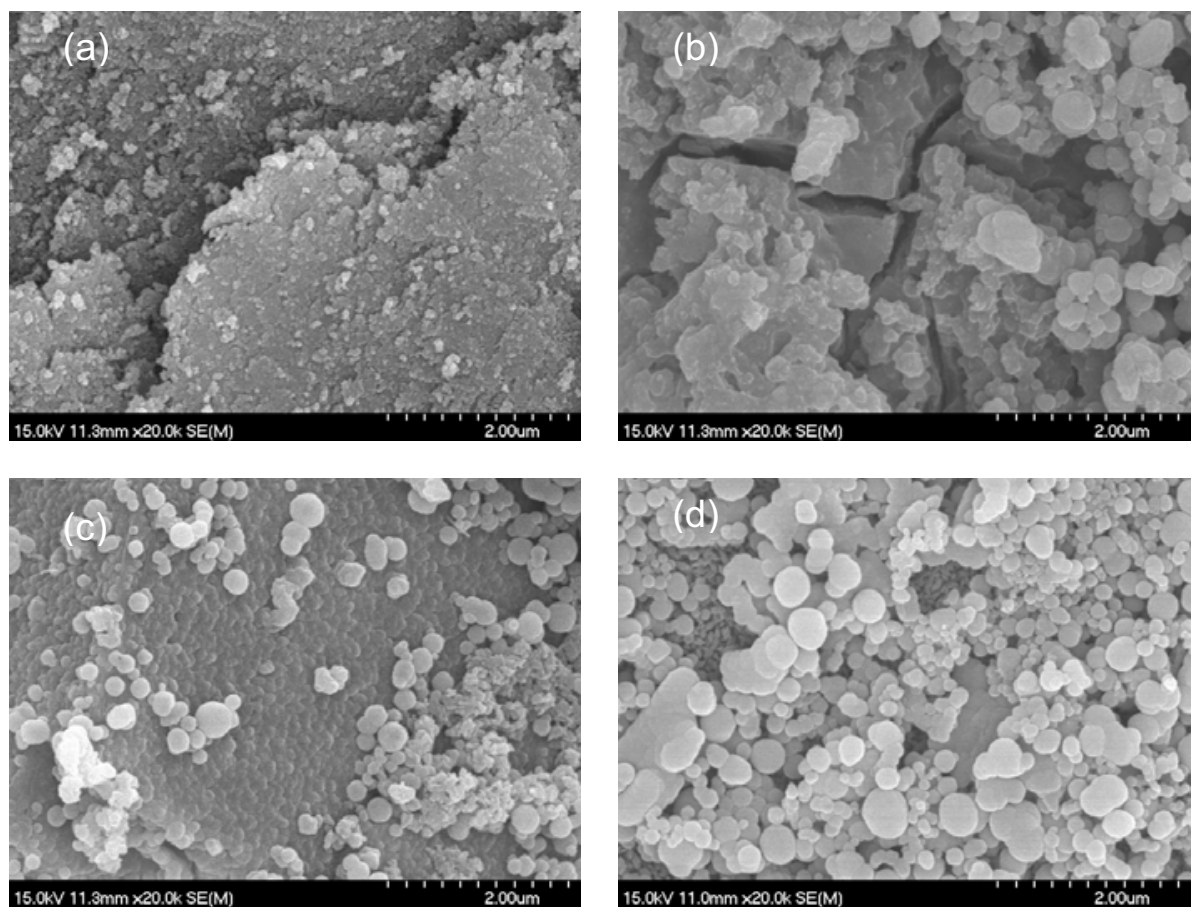

Fig. 1. FE-SEM images of the $\mathrm{ZnO}$ prepared with different $\mathrm{pH}$ regulators. (a) $0.2 \mathrm{M}$ hydrogen peroxide, (b) $0.2 \mathrm{M}$ oxalic acid, (c) $0.2 \mathrm{M}$ sodium hydroxide and (d) $0.2 \mathrm{M}$ citric acid.

\subsection{Effect of the Electrolyzer on the Morphology of ZnO}

The effect of the electrolyzer reflects in blocking on the movement speed of ions[20]. Similar to the process of anodic etching of Ti foil, there are two layers in the vertical attitude of $\mathrm{Zn}$ foil, as described in the Fig. 2d. The upper layer consists of $\mathrm{ZnO}$ while the under is composed of unreacted $\mathrm{Zn}$. Two reaction steps, namely the generation and the dissolution of nano- $\mathrm{ZnO}$, determine the morphology of the oxide layer of $\mathrm{ZnO}$ during anodizing. Surface morphology of $\mathrm{ZnO}$ layer in different electrolyzer are shown in Fig. 2a, $\mathrm{b}$ and $\mathrm{c}$. It can be observed that the composition of electrolyte plays an important role on 
the degree of the uniformity of the $\mathrm{ZnO}$ layer. Cracks can be seen everywhere on the surface in pure $\mathrm{H}_{2} \mathrm{O}$ (Fig. 2.a) and the surface in glycol/H2Oelectrolyzer is much rough and uneven by random etching (Fig. 2.c). Meanwhile, the surface of $\mathrm{ZnO}$ is uniform in ethanol/ $\mathrm{H}_{2} \mathrm{O}$ ((Fig. 2.b). Further, nanoparticles with disc-like shape can be seen in all of the enlarged images (the inset micrograph in Fig.3.a, b and c). The distribution and the shapes of $\mathrm{ZnO}$ nanoparticles in the Fig.2b are also more uniform and clearer than the other two samples, which indicates that the stable anodization in ethanol/H2Oelectrolyzer.

The effect of electrolyzer may be originated from the difference in viscosity or the movement speed of $\mathrm{H}^{+}, \mathrm{F}^{-}$and $\mathrm{NH}_{4}{ }^{+}$ions, which will influence the generation and the dissolution rates of nano- $\mathrm{ZnO}$. Appropriate viscosity can cause proper movement speed and the uniform surface come into being. According to research before, the movement of ions in solution can simplified as two-orientation strength model (Fig.3d), of which one is parallel to the face of anode, the other is vertical to it. The parallel strength contributes to concentration distribution while the vertical to generation/dissolution of $\mathrm{ZnO}$ nanoparticles. Pure water has little viscosity that the vertical strength dominates the anodization process, leading to fast etching of $\mathrm{ZnO}$ nanoparticles (Fig.3a). On the contrary, the proper viscosity of ethanol/H2O brings the uniformity(Fig.3b).
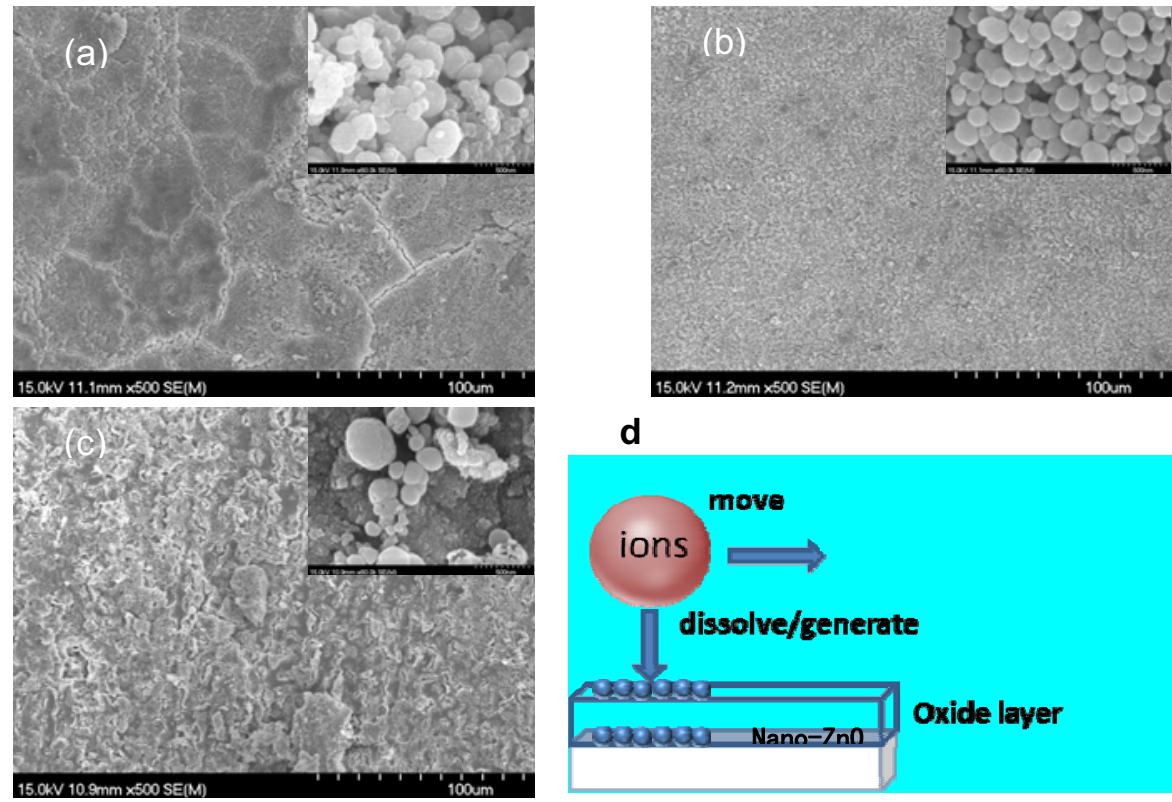

d

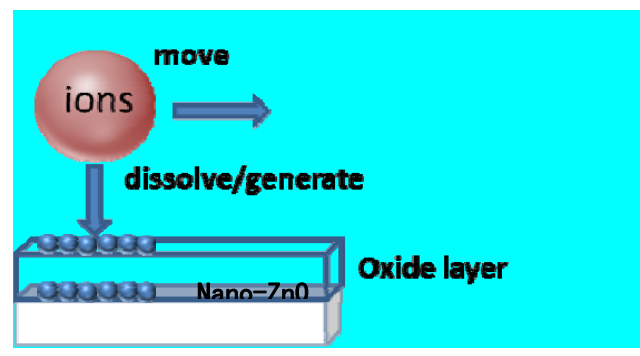

Fig. 2. FE-SEM images of $\mathrm{ZnO}$ layer prepared with different electrolyzer. (a) pure $\mathrm{H}_{2} \mathrm{O}$, (b) $\mathrm{H}_{2} \mathrm{O}: \mathrm{C}_{2} \mathrm{H}_{5} \mathrm{OH} 1: 1$,(c) $\mathrm{H}_{2} \mathrm{O}$ : glycol 1:1. (d) the scheme of $\mathrm{Zn}$ anodizing

\subsection{Effect of NH4F Concentration on the Morphology of ZnO}

$\mathrm{NH}_{4} \mathrm{~F}$ concentration plays a key role in controlling the surface morphology. Different concentrations cause the different nanostructuress on the surface. Low concentration of $\mathrm{NH}_{4} \mathrm{~F}$ leads to $\mathrm{ZnO}$ nanosheets(Fig. 3a) while high concentration forms discal $\mathrm{ZnO}$ nanoparticles. Reaction (3) can help us to understand this interesting phenomenon. It can be seen that the competitive reactions of the generation and the dissolution of $\mathrm{ZnO}$ determine the growth speed and the morphology of nano- $\mathrm{ZnO}$. At low $\mathrm{NH}_{4} \mathrm{~F}$ concentration, the 
amounts of ions is not enough to break the $\mathrm{ZnO}$ layer into pieces (nanopaticles) and the nanosheets come into being. If the concentration of $\mathrm{NH}_{4} \mathrm{~F}$ is too high, excessive ions will increase the dissolution rate of the nano- $\mathrm{ZnO}$ species and only left tiny $\mathrm{ZnO}$ particles.
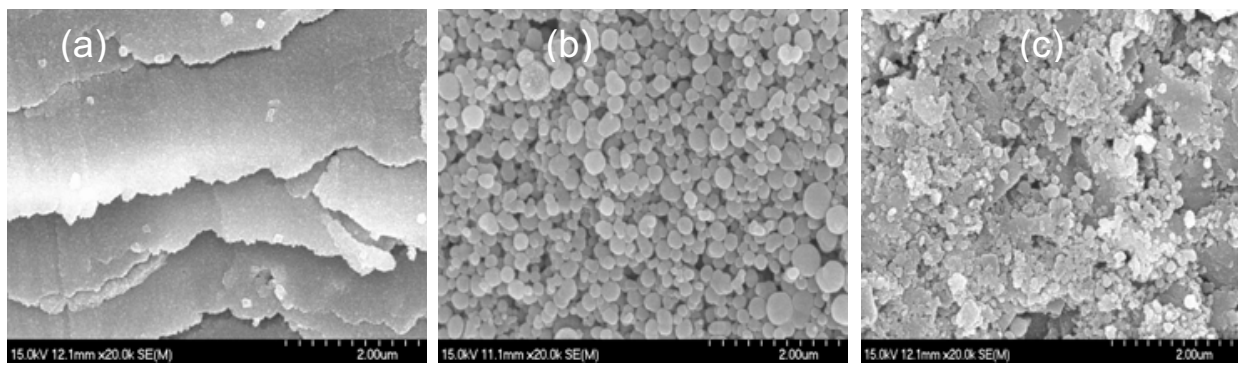

Fig.3. FE-SEM images of nano- $\mathrm{ZnO}$ prepared with different $\mathrm{NH}_{4} \mathrm{~F}$. (a) $0.5 \% \mathrm{NH}_{4} \mathrm{~F}$ (b)

$$
1 \% \mathrm{NH}_{4} \mathrm{~F} \text { (c) } 1.5 \% \mathrm{NH}_{4} \mathrm{~F} \text {. }
$$

\subsection{Effect of Temperature and Reactive Voltage on the Morphology of ZnO}

Other anodization conditions, such as the temperature and the reactive voltage, also can affect the balance between the two reactions and the final $\mathrm{ZnO}$ morphologies. The results are shown in Fig. 4 and Fig.5. With the reaction temperature increases, the shapes of $\mathrm{ZnO}$ nanoparticles changes to be irregular and the size distribution changes to more random. It is likely that increment of the temperature influences the ionic migration and accelerates the generation and dissolution rate of $\mathrm{ZnO}$ in varying proportions. As a consequence, the generation and dissolution balance of $\mathrm{ZnO}$ nanoparticles is influenced.
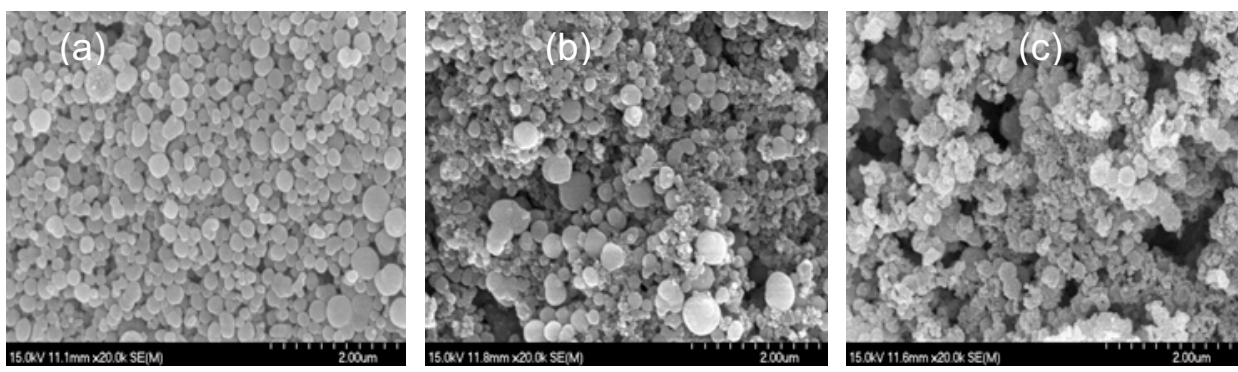

Fig.4. FE-SEM images of nano- $\mathrm{ZnO}$ prepared at different temperature. (a) $25^{\circ} \mathrm{C}$ (b) $35^{\circ} \mathrm{C}$ (c) $45^{\circ} \mathrm{C}$.

Fig.5. shows the FE-SEM images of sample prepared in $1 \%$ $\mathrm{NH} 4 \mathrm{~F}$ (quality score) solution ( $\mathrm{H} 2 \mathrm{O}: \mathrm{C} 2 \mathrm{H} 5 \mathrm{OH} 1: 1$ ) at $25^{\circ} \mathrm{C}$ and $0.2 \mathrm{M}$ citric acid as $\mathrm{pH}$ regulator for $10 \mathrm{~min}$ with various anodization voltage. From these images it is seen that the influence of voltage seems to be more remarkable. The discal $\mathrm{ZnO}$ nanoparticles only can be formed at $40 \mathrm{~V}$ anodization voltage. It is probably because the function of voltage is demonstrated in two aspects. First, voltage is the necessary driving force to the formation of $\mathrm{Zn}^{2+}$ :

$$
\mathrm{Zn} \rightarrow \mathrm{Zn}^{2+}+2 \mathrm{e}^{-}
$$


At the initial stage of the reaction, $\mathrm{Zn} 2+$ is formed on the $\mathrm{Zn}$ foil as reaction(3) described. At high anodization voltages $(50 \mathrm{~V}$ and $60 \mathrm{~V})$, the electrochemical anodization speed was very fast. On the other hand, it can accelerate the movement of ions in solution perpendicular to the face of anode. As we have discussed above, the morphology of nano- $\mathrm{ZnO}$ species varies along with the speed of ionic movement. High anodization voltages $(50 \mathrm{~V}$ and $60 \mathrm{~V})$ enlarge the perpendicular speed, leading to various morphologies of nano- $\mathrm{ZnO}$ species.
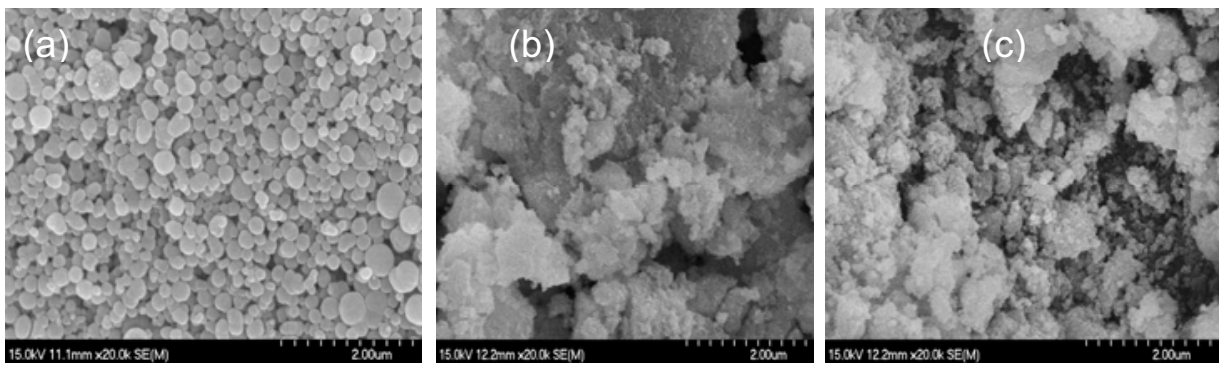

Fig.5. FE-SEM images of nano-ZnO prepared under different voltages. (a) 40V(b) 50V (c) $60 \mathrm{~V}$

\subsection{Photocatalytic Reduction Activity of CO2}

The catalytic activity of $\mathrm{ZnO}$ was tested by the photocatalytic reduction of $\mathrm{CO}_{2}$. Transformation of the $\mathrm{CO}_{2}$ to hydrocarbons is a positive direction to solve the lack of energy and the ever-increasing $\mathrm{CO}_{2}$ concentration[21]. Much attention has been paid to semiconductor photocatalyst especially modified $\mathrm{TiO} 2$ in recent years[22 24]. A single semiconductor does not effectively generate and separate electron-hole pairs. As a wide band gap semiconducting oxide, $\mathrm{ZnO}$ have been expected. Its energy gap a little greater than $\mathrm{TiO} 2$ can reach to $3.3 \mathrm{ev}$ (Fig.6b) that bring in bigger reduction potential. The performance of $\mathrm{ZnO}$ is considered to be influenced by the nanoscale morphologies. The $\mathrm{ZnO}$ material with discal shaped nanoparctiles shows rather high photocatalytic reduction activity of $\mathrm{CO} 2$ from Fig.6a. The yield of $\mathrm{CH}_{4}$ reaches 2.48 umol/gcatalyst, which is as ten times as the other two samples. The efficiency of $\mathrm{ZnO}$ could expect to be further improved by altering the morphologies.

(a)

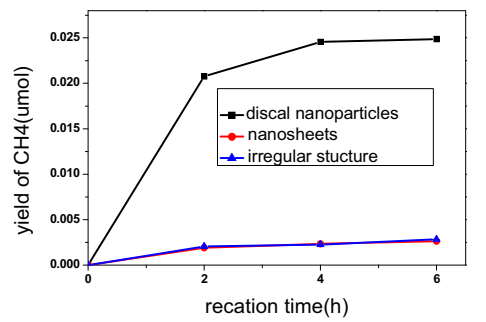

(b)

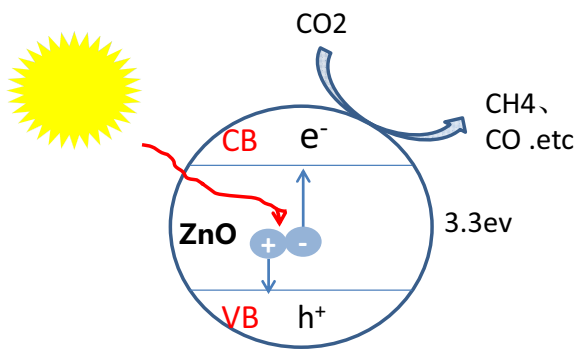

Fig.6. (a) yield of $\mathrm{CH} 4$ with $0.01 \mathrm{~g}$ different nano- $\mathrm{ZnO}$ structure as catalyst. (b) Schematic illustration of photoinduced generation of an electron-hole pair in $\mathrm{ZnO}$ semiconductor that catalyze $\mathrm{CO}_{2}$ photoredox. 


\section{Conclusion}

Nano $\mathrm{ZnO}$ material was fabricated by anodization process. The influence of the different anodization conditions, such as the $\mathrm{pH}$ regulater,theelectrolyzer, the NH4F concentration, the temperature and voltage are investigated in detail. The morphology of as-prepared $\mathrm{ZnO}$ material was determined by the generation, the dissolution and the movement of nano- $\mathrm{ZnO}$ species during anodization. It is under the conditions of $0.2 \mathrm{M}$ citric acid as $\mathrm{pH}$ buffer, electrolyzer $\left(\mathrm{H}_{2} \mathrm{O}: \mathrm{C}_{2} \mathrm{H}_{5} \mathrm{OH} 1: 1\right), 1 \% \mathrm{NH}_{4} \mathrm{~F}$ (quality score), $25^{\circ} \mathrm{Cand} 40 \mathrm{v}$ that an nano $\mathrm{ZnO}$ material with discal shaped nanoparticles is obtained. The $\mathrm{ZnO}$ material is supposed to be good for phothoncatalyst application due to its regular structures. it's the yield of $\mathrm{CH} 4$ over the $\mathrm{ZnO}$ material can reach to $2.48 \mathrm{umol} / \mathrm{g}$ in photocatalytic reduction of $\mathrm{CO}_{2}$.

\section{References}

1. M. Guo, P. Diao, S. Cai, Hydrothermal growth of perpendicularly oriented ZnO nanorod array film and its photoelectrochemical properties, Appl. Surf. Sci. 249 (2005) 71-75.

2. W.J. Lee, A. Suzuki, K. Imeda, H. Okada, A. Wakahara, A. Yoshida, Fabrication and Characterization of Eosin-Y-Sensitized ZnO Solar Cell, Jpn. J. Appl. Phys. 143 (2004) 152-155.

3. M.H. Huang, S. Mao, H. Feick, H. Yan, Y. Wu, H. Kind, E. Weber, R. Russo, P. Yang, Room-Temperature Ultraviolet Nanowire Nanolasers, Science 292 (2001) 1897-1899.

4. B. Pal, M. Sharon, Enhanced photocatalytic activity of highly porous $\mathrm{ZnO}$ thin films prepared by sol-gel processMater. Chem. Phys. 76 (2002) 82-87.

5. X.D. Bai, E.G. Wang, P.X. Gao, Z.L. Wang, Measuring the work function at a nanobelt tip and at a nanoparticle surface, Nano Lett. 3 (2003) 1147-1150.

6. J. Johnson, H. Yan, P. Yang, R. Saykally, Optical cavity effects in $\mathrm{ZnO}$ nanowire Lasers and Waveguides, J. Phys. Chem. B 107 (2003) 8816-8828.

7. S. Sreekantan, L. R. Gee, Z. Lockman, Room temperature anodic deposition and shape control of one-dimensional nanostructured zinc oxide. J. Alloys Compd. 476(2009) 513-518.

8. L.T. Canham, Silicon quantum wire array fabricated by electrochemical and chemical dissolution of wafers, Appl. Phys. Lett. 57 (1990) 1046-1048.

9. O. Jessensky, F. Muller, U. Gosele, Self-organized formation of hexagonal pore arrays in anodic alumina, Appl. Phys. Lett. 72 (1998) 1173-1175.

10. D. Gong, C.A. Grimes, O.K. Varghese, W. Hu, R.S. Singh, Z. Chen, E.C. Dickey, Titanium oxide nanotube arrays prepared by anodic oxidation, J. Mater. Res. 16 (2001) 3331-3334.

11. J. M. Macak, H. Tsuchiya and P. Schmuki, High-aspect-ratio TiO2 nanotubes by anodization of titanium, Angew. Chem. Int. Ed. 44 (2005) 2100-2102.

12. H. Tsuchiya, J.M. Macak, I. Sieber, L. Taveira, A. Ghicov, K. Sirotna, P. Schmuki, Self-organized porous WO3 formed in NaF electrolytes, Electrochem. Commun. 7 (2005) 295-298.

13. H. Tsuchiya, P. Schmuki, Self-organized high aspect ratio porous hafnium oxide prepared by electrochemical anodization, Electrochem. Commun. 7 (2005) 49-52.

14. I. Sieber, H. Hildebrand, A. Friedrich, P. Schmuki, Formation of self-organized niobium porous oxide on niobium, Electrochem. Commun. 7 (2005) 97-100. 
15. S.J. Kim, J. Lee, J. Choi, Understanding of anodization of zinc in an electrolyte containing fluoride ions, J. Electrochim. Acta. 53(2008) 7941-7945.

16. S.J. Kim, J. Choi, Self-assembled arrays of $\mathrm{ZnO}$ stripes by anodization, Electrochem. Commun. 10 (2008) 175-179.

17. S.S. Chang, S.O. Yoon, H.J. Park, A. Sakai, Appl. Surf. Sci. Luminescence properties of anodically etched porous Zn, 158 (2000) 330-334.

18. M. Izaki, Preparation of transparent and conductive zinc oxide films by optimization of the two-step electrolysis technique, J. Electrochem. Soc. 146(1999) 4517-4521.

19. C.Y. Kuan, J.M. Chou, I.C. Leu, M.H. Hon, Formation and field emission property of single-crystalline Zn microtip arrays by anodization, Electrochem. Commun. 9 (2007) 2093-2097.

20. C.A. Grimes, G.K. Mor, Fabrication of TiO 2 nanotube arrays by electrochemical anodization: four synthesis generations, in: TiO 2 Nanotube Arrays, Springer, 2009, pp. $1-66$.

21. C. Wang, J. Li, L. $\mathrm{Xu}$, Reduction of $\mathrm{CO} 2$ aqueous solution by using photosensitized-TiO2 nanotube catalysts modified by supramolecular metalloporphyrins-ruthenium(II) polypyridyl complexes. J. Mol. Catal. A-Chem. 363 (2012) 108-114.

22. M. Reli, K. Kamila, M. Vlastimil, K. Pavel, O. Lucie, Effect of calcination temperature and calcination time on the kaolinite/Tio2 composite forphotocatalytic reduction of CO2, GeoSci. Eng, 58 (2012) 10-22.

23. K. Satoshi, K. Hidekazu, O. Kiyohisa, M. Takayuki, S. Akira, Photocatalytic reduction of $\mathrm{CO} 2$ using $\mathrm{TiO} 2$ powders in liquid $\mathrm{CO} 2$ medium, J. Photochem. Photobiol. A 109 (1997) 59-63.

24. C.J. Wang, R.L. Thompson, J. Baltrus, C. Matranga, Visiblelight photoreduction of $\mathrm{CO} 2$ using $\mathrm{CdSe} / \mathrm{Pt} / \mathrm{TiO} 2$ heterostructured catalysts, J. Phys. Chem. Lett. 1 (2010) 48-53. 